

precautions are taken in many works, that the effluvia arising are far more noticcable at a distance than they are in the works themselves. There is therefore but little doubt that trade nuisances are in many instances sources of ill-health to many otherwise healthy people exposed to their influence; much more then must they be injurious to weakly people and invalids, who are more easily affected by conditions tending to lower the standard of healtl.. That such is the case is found to be the result of some years' experience, and we may assume, therefore, that as the result of theory and practice, any causes which tend to make impure, even in a small clegree, the air we breathe, are potent means for lowering that vitality which it is the aim of sanitary science to maintain.

One more point in connection with this subject demands a moment's attention, viz., the allegation sometimes made that some effluvia arising from works are disinfecting in their character, and therefore a blessing in disguise. I have heard this statement made in all seriousness in the high courts, in relation to a nuisance arising from the making of charcoal. If, however, we consider for a moment that for these agents to be of any use as disinfectants they must be present in sufficient quantity to exert a dearlly influence on the contagia, we see that the infinitesimal quantities diffused in the atmosphere can have $n$ effects as disinfectants or germicides, but can only irritate and damage the health of the higher living organisms exposed to them.

I will now proceed to deal with the actual nuisances arising, and first draw your attention to

\section{The Iímeping of Animals.}

Horses, or rather stables, only give rise to effluvia when improperly kept, either from insufficient air space around and inside the stables, or from a want of cleanliness in the stable, or on the ground adjoining it. If large stables, as is sometimes the case, are placed between long rows of houses. a persistent orlour of ammonia is generally noticel, dne to the decomposition of urine of the horses and the fact that the stable is improperly kept, and owing to the impossibility of thorough aieration and diffusion. A gain, it is frequently found that in large stables no care is taken as to the early removal of dung and other filth, and while this remains and when it is being removed, intolerable nuisance frequently arises. Another cause of nuisance in stables is the improper character of the paving which allows soakage of animal filth into the ground. A favourite kind of paving being the rounded "kidney" stones, which being only laid on porous surfaces not only allow grouml pollution to take place 
but can never from the nature of them be properly cleansed. In addition to the public nuisance, it must be borne in mind that dwellings are of ten found over stables, and unless constructed with a due regard to the sitnation, all effluvia arising in the stable will pass into them to the detriment of the health of the dwellers. These people are generally horsekeepers or grooms, and though they may not sce anything to complain about, the condition of their health and that of their families becomes rightly the care of the Sanitary Officer.

Cow keeping.-Nuisances arise from this trade from improper position of the cowsheds, improper construction of cowsheds, insufficient air space and ventilation for the cows, dirty condition of cows and sheds, storage of dung, \&c., on or too near premises. Many cowsheds exist even in large towns which are not in any way a nuisance. Another cause of nuisance is the storage in improper receptacles and improper quantities of brewers' grains and distillers' wash, largely used for the feeding of cows in towns.

Pig leepinq.-Everyone knows that pig keeping generally causes a nuisance if it be carried on near dwellings. This is not because the pig naturally is an unclean animal, but because it is kept and fed in such an objectionable way. The causes of nuisance are the filthy condition and improper character of the styes, and the nature, preparation and mode of storage of the food. The styes are generally unsuitable outbuildings, or else little huts made of wood and capable therefore of absorbing the filthy liquicls abounding. They are rarely properly drained, sometimes all the excreta and filth being conveyed simply into a hole in the ground just outside the stye and allowed to soak away. The paving, if there be any, is absorbent, consisting of porous bricks or stones and not allowing of proper cleansing. As regarils the food, this is generally stored in tubs, sometimes in brick pits; these are rarely, perhaps never, cleaned out, and containing as they do, all sorts of animal and vegetable matter in a state of decomposition and fermentation (for any thing is thought good enough to give to the pigs), when these are stirred up then a nuisance of the most offensive kind arises; and I have known cases in Rural Districts where the nuisance has given just cause of offence to people outside the farm and a considerable distance away, while no nuisance arose actually from the pigs themselves or their styes. Sometimes too nuisance arises from the boiling of offal in preparation for food. In order to shorten the subject I have refrained from mentioning under each hearl the means to be adopted to abate these nuisances, and will now therefore touch upon this important section of the sulject. 
From Horse leeping.-The paving should be impervious, and this is best effected by its being jointless. Ordinary bricks do not make a good pavement, if they are used they should be laid on rough concrete and laid in cement. The drain should be properly laid and discharge on to a trap outside. The dung sliould be removed at short intervals, and if straw or similar litter be used, it must be frequently changed or it becomes ammoniacal. I have found however that much of the effluvia arising from stables is done away with if peat moss is userl as litter, as it absorbs and deodorizes all the urine. It is cheaper than straw, is soft and warm, and as a sanitary agent, deserves an extended use. Grooms object to it on account of appearance, but I feel sure that its use will be much extended in the future.

If there are any dwellings over the stable, the floor between them and it must be made impervious and the staircase to them must have no connection with the stable.

Cow keeping.-As in the case of keeping horses the muisances arise from improper construction of cowsheds, from uncleanliness and the improper storage of food. Cowsheds rarely give enough space, each cow should have at least 800 cubic feet, though in some sheds they do not have 250. The sheds should be built of impervious material and be properly ventilated. The paring must be impervious and the drainage good; no dung should be allowed to be stored inside the shed, nor should it be stored for any length of time near, it should be removed as quickly as possible.

The feeding troughs should be of iron and be kept clean, while there should be an ample supply of water within the shed so that cleanliness may be practiced. There should be sufficient air-space round the shed. Grain if stored should be kept in brick pits or other non-absorbent vessels, and be protected from the weather, and these pits must when emptied be thoroughly cleansed, or the acetous fermentation will cause au intolerable nuisance.

Pig keeping-requires great care if carried on near dwellings. No wooden styes should ever be allowed and of course cleanliness both of stye and food is of the highest importance. Pigs and their litter should be cleansed daily, and every part of the stye should be of an impervious material; the drainage must be good and the food or wash should be stored only in proper ressels and not at all if sour or offensive, and in no case should pigs be kept within forty feet of a human haljitation.

\section{The Slaughtering of Animals.}

This very important branch of trade unless properly carried on is a fertile source of nuisance. It is carried on in public 
slaughter-houses or abattoirs and also in private slaughterlouses, and it is to these latter I would direct your attention. These private slaughter-houses are generally close to butchers' shops, and indeed in some places the operations are performed in the shop itself. I need hardly say that any such proceedling should not be tolerated. The nuisance arises from two main causes, the keeping of the animals prior to slaughtering, and a want of cleanliness in the slaughter-house after the operation. It is important then that specific precautions to prevent nuisance should be adopted. (The bye-laws issued by the L. G. B. as to structure should be referred to.)

In addition to this the occupier must provide proper ressels for catching and recciving blood and offal, and these must be removed from the premises on the same day, and he shall, as far as possible, prevent blood and offal gaining access to the drain or sewer, and the blood pit should not be only cleansed, but disinfected. The butcher as a rule has no difficulty in getting rid of the blood and offal. The blood is used as food, also in Turkey-red dying, while the guts are fetched by the gutscraper, and the horns, hoofs and skins are all easily saleable.

The Slaughtering of Horses. - This comes into the sime category as slaughtering beasts, $\mathbb{E} c$., but as a nuisance it is likely to be more serious, first because the material operated on is generaliy discased, and emanations arising from it are likely to be more injurious to health; and secondly, because in acldition to slaughtering the knacker nearly always prepares, by boiling, offal and flesh as food for eats and dogs. The knacker also receires as part of his business dead carcases, and nuisance may arise from these before proper disposal. (The regulations made by the London County Council should be referred to.)

\section{III.-Industries in which Anmal Matters are dealt WITH.}

The Frying of Fish is a rery general operation in the poorer portions of large towns, and gives rise to considerable nuisance to those classes of people who do not buy the fish. The nuisance arises from the fumes from the oil in which the fish is fried (generally cotton-seed oil). It is very far reaching and not easy to abate. The operation is generally carried on in a small shop on an open fire. The plan usually adopted to abate the nuisance is the provision of a hopper over the dish connected with the chimney, but as this cannot be brought right down, at least in front, where it must be open for observation, draughts frequently cause the fumes to be blown about. The chimney should be so constructed as to have a good draught, and it should be carried up above the neighbouring houses. 
Trade of a Fellmonger.-This consists in receiving the skins of sheep and preparing them for the leather dresser. The skins received are of two kinds-fresh English skins from the butcher's, and foreign skins. The English skins are dealt with as follows: they are first beaten with a mallet, to detach any lumps of dirt, then soaked and washed with water. They are then limed, either in a pit or by being brushed over on the fleshy side with a cream of lime.

They are next hung up, either in a yard or in a warmed room, for the purpose of having the wool loosened. The wool is then removed by hand and placed in bins, when afterwards the skin, or peli as it is now called, is thrown into a pit of milk of lime, where it remains till it goes to the leather dresser. Foreign skins being hard are first soaked in water for several hours, and after the "lurring" of the wool is completed, are hung up to taint, by which the wool is loosened. They are not limewhited. The chief sources of nuisance in this trade are: (1) The reception of raw skins from the butcher's. (2) The odlour arising from the limed and drying skins. (3) The emptying of the pits. (4) The storing on the premises of used and waste lime. (5) The odour arising from dirty yard soaked with organic matter. (6) The nuisance caused below the works when the washing is done in a running stream.

It is easy to see that no nuisance need occur in this trade, i.e., no nuisance beyond the works and yard; cleanliness both of the skins and wash-water, which should be changed once or twice a day, is essential. The waste lime should be removed in covered carts at once, while the yard should be properly paved and kept clean.

Leather Dressing.-Sometimes this is used in the same sense as tanning, but as a rule this trade only deals with sheep skins or pelts, and the tanner with bullock's hicles.

The pelts are first "fleshed" or cleaned with a double-handed knife, so as to remove all pieces of tissue. They then go into pits containing milk of lime, first used weak and afterwards stronger, the process lasting some days. Then they are cleaned in tanks of water, being as a rule kept in constant motion; finally they are "puered" or" soaked for some time in a solution of dogs' dung, which in winter is warmed, and is of course horribly offensive, after which they are tawed or tanned. Nuisance may arise from dirty surroundings, improperly paved yards and floors, and from the operation of puering; this latte should only be carried out when the stench arising is carried away by flues and shinfts out of reach of houses or public roads.

Tanning-may give rise to serious nuisance, the processes carried on are as follows: hides which may be (1) fresh 
English ; (2) salted hides ; (3) dry lides or "kips; are first of all "limed" or soaked in pits containing lime and water, then "unhaired," i.e., the hair lonsened by the lime is removed. It is then "fleshed" or has the loose inner tissue removed, the fleshings being sent to the glue maker. "Rounding" then takes place, i.e., the irregular parts about the shoulder's are cut off and sent to the glue maker. They are now termed "butts." Next the butts are soaked in clean water for a few hours to remove lime, and are then put into the "graining pit" which contains a solution of pigeons' or fowls' duug, or sometimes even a solution of weak ammonia, this softens the butts as "puering" softens the pelts.

"Scudding" is the next process. The hides are placed on the beam and are cleaned with a knife like an unhairer, and are finally shaved with a razor-like instrument to remove the fine hairs.

"Splitting" of those hides that are to be split is now performed, when the final process of "tamning" proper is commenced. This consists in soaking the butts in pits containing old tan liquor which is of course comparatively weak, then in pits called "floaters," which contain tan liquor of gradually increasing strength, until they are placed in clusters, i.e., pits containing rery strong bark liquor with crusted lark sprinkled over the top. This process takes time, the whole operation lasting about ten months. The substances used are oak bark, nimosa bark, valonia, catechu or gambier. The sources of muisance from tanneries are as follows: (1) Offensive hides, generally cured foreign hides. (2) Old "soaks" which are only occasionally cleaned, and are generally very offensive. (3) The handling of the hides when changing them from the pits. (4) The scraping processes. (5) The running of old "soaks" into drains or sewers. (i) The destruction of the waste tan by burning.

The remedies are plain : 1st, the removal of hides to the tannery should be in covered carts only, while it is probable that much good would result by disinfecting the fleshy side of the hide; this indeed las been done. Old soaks might be disinfected when being cleared out, sulphate of iron being used, while it is more than doubtful if the use of old soaks is of any advantage to the tamner. Cleanliness of the yards must be insisted on, while if the waste tan is burnt it must not be in heaps, but either under the boiler fires or in an oven constructed for the purpose, commected with a tall chimney shaft.*

* The waste tan is now sometimes passed through a press, dried thereby, and sold as litter for auimals. 
Chamois leather making sometimes causes nuisance from the fish oil used in its manufacture, and when the skin is dried in a chamber the odour of acrolein is noticeable. Arrangements can be made by which the oiling is so carried on that the fumes are led into a shaft and carried away a sufficient height, or are burned in a furnace fire.

Glue making.-The materials used in this trade are: (a) wet materials, such as "spetches" or fleshings from leather dressers and tanners, ears of animals, portions of bones to which tendons are attached, \&c.; (b) dry materials, dimaged pelts (Australian), ox feet, horn "sloughs" (pith or core), clippings of parchment, \&c. The first process consists of liming if they have not been so treated. Then the lime has to be got rid of by washing in tanks or pits. Then the pieces are boiled in large open pans of such construction that there is a false bottom to allow of the circulation of the liquid to prevent burning and to assist the straining off of the liquid glue, while the boiling is going on the pans are constantly stirred. When the operation is completed, the pans are allowed to cool and the glue is drawn off from the space below the false bottom along a wooden chamnel to troughs called "coolers," into which it solidifies into a firm jelly, which is finally cut up into blocks, and these are allowed to dry spontaneously in wooden sheds. The substance left in the pans is called "scutch." This is usually after removal sent to the manure makers.

Size is made in much the same way, the materials used depending on the use to which it is to be put.

Glue works are often a source of considerable nuisance, effluvia having been noticed at Bristol for nearly a quarter of a mile from the works. The sources of nuisance are as follows: (1) accumulations of "fleshings" where the deliveries of these are in excess of power to deal with them; (2) the effluvia from the boiling pans, which, if the materials are old and decomposed, is disgusting in the extreme; (3) the accumulation of "scutch," which sometimes goes on for long periods. Dr. Ballard describes the odour of an old accumulation of decomposing "scutch" as "ferocious and sickening"; (4) general efthuia arising from untidy works. It is not necessary that glue works should be a nuisance, and their mode of conduct to obviate this is well expressed in the bye-laws for their control, passed by the London County Council (q. v.).

The boiling of Hesh, tripe, $\delta$ c., and the preparation of Neats-foot Oil.-The boiling of flesh is usually carried on at knackeries in pans generally situated in the slaughterhouse, sometimes these are heated by open fires and sometime by steam thrown in, the fat is skimmed off and sent to soap boilers, while 
the boiled flesh is placed on the floor of the slaugliter-house and afterwards hung up to dry. The liquor is ladled out hot and thrown on to an open chanuel and down into a drain. Tripe is the first stomach of the $\mathrm{Ox}_{\mathrm{x}}$, and this is first cleaned and scalded and then scraped, generally by hand, it is afterwards boiled in open pans, the fat skimmed off and set aside. When the tripe is sufficiently cooked it is hung up to cool, and the boiling liquor is discharged into the drains.

Neats-foot Oil is made from $\mathrm{Ox}$ feet. These are washed in cold water and then boiled in open pans, when the oil is skimmed off the surface.

It will be at once seen that all these processes if badly conducted are likely to yield efthuria. The sources of nuisance in the establishments being: (1) the vapours arising from the boiling pans; these are specially bad at knackeries, particularly in close muggy weather; (2) the vapours arising from the boiled materials whilst cooling; (3) the vapours arising from the lifuor runuing into the drain; (4) general untidiness and want of cleanliness of the place itself.

These nuisances can be dealt with as follows : in small tripe and trotter boiling places the boiling-pan should have a hopper fixed over it, and connected with a high chimney having a good draught; it will not do to allow the steam simply to escape through a loole in the wall at a low altitude. In larger places the lid should fit closely, and a pipe should take the vapours down beneath the fire-place, where they will pass through the fire and be consumed. The ash-pit of course must have a wellfitting door. For large establishments, such as linackeries, the plan adopted at Adams's, in Birmingham, is about the best. It is as follows: six boilers are arranged side by side, each having a wooden lid fastened tightly on. At the top of each pan is a pipe which connects with a ten-inch main pipe, and this is connected with a condenser ontside the building. This condenser is about fourteen feet long, is macle of sheet iron, and filled with coke, and is liept cool by being exposed to the atmosphere. It is inclined at an angle, and a pipe at its lower border leads away the condensed vapour. The upper end is connected with the chimney by two pipes. I should add that the boilers are themselves placed in a sort of closet, and when the pans require an examination a sliding door enables this to be made, while any issuing steam rises to the top and finds access through a waste pipe into the chimney. The second source of nuisance may be remedied by placing the flesh to cool in pans of cold water; while the third is obviated by allowing the liquor to cool before it enters the drain. As regards the fourth, cleanliness must be insisted on; while the 
processes should only lye allowed in those premises properly paved and impervious, and structurally suitable, and having non-absorbent ressels for the reception of garbage and offal.

Fat melting and Candle making.-The materials used are kitchen fat, pig's fat, and butcher's fat, consisting of beef and mutton fat mixed. The following are the methods adopted: (1) if the fat is melted in an open pan, it is first cut up into small pieces; (2) these are then placed in the pan and heated, the pan being kept stirred by a workman with an iron stirrer to prevent burning.

The other plan consists in heating the fat by steam alone, or by steam, sulphuric acil having previously been added; when this is the case the boiler must be lined with lead, and as the ingress of the steam itself causes agitation no stirring is required. At other works the fat is melted in steam jacketer pans; (3) the rendering completed, the tallow is ladled out into open pans, sometimes after being strained ; (4) the next process is the further pressing of the refuse left in the pans, gencrally by a screw or hydraulic press to further extract fat by which what is known as "greares" is made.

The following are the sources from which nuisances may arise : (1) storing of old and rancid fat, this however never extends far; (2) the rapours from the melting pan, especially from those open ones heaterl by fire, when the stirring has been neglected and also when the fat is old and rancid; (3) during the laclling out, especially towards the end, as these portions are likely to become over-heaterl, nuisance may arise; (4) greaves pressing, as it is done while the tallow is hot enough to give out vapours; (5) filthy and dirty condition of premises and ressels, owing to the presence of stale and rancid grease.

It will be at once seen that all these nuisances are very easily prevented: (1) by using only sweet fat; (2) loy steam melting. 'This should always be insisted on in towns, though fat-melters object to adopt the plan because they lose the profit to be obtained from the "greaves." If the fat is melted in open pans then these should have iron jointed lids and the vapours should be conducted as previously mentioned beneath the fire. If steam melting be adopted thein the vapours can be collected by shafts and conducted into tall chimneys or through a fire, or as is sometimes done, a partial condensation may be first effected; this nuisance occurring from ladling out the fat can only be dealt with very partially by the provision of a hood over the pan; (4) the nuisance from "greaves pressing" can be abated by closely boxing up the press and leading the vapours to a shaft ; while (5) cleanliness, scraping, washiug, and limewhiting will of course reduce the nuisance produced by untili- 
ness, Sc., to a minimum, and at the same time in the end conduce to financial success.

Soap boiling or soap making used to be a rery offensive trade previous to the introluction of British alkali, now however it can be conducterl practically without nuisance, and when effluvia do arise it is chiefly in connection with the melting of fats, and this of course can be dealt with on the principles previously stated.

blood drying, blood boiling, the mannfacture of blood albumen.These trades all tend to produce nuisance: (1) from decomposed blood being used; (2) the peculiar odour due even to fresh bloot, but more marked when cleanliness is not observed; (3) effluvia from blood boiling, especially in open pans by fire heat, and when the blood is decomposed, and lastly from blood manure making, which is frequently carried on in the same premises. In populous places steam heat only should be applied, while perfect cleanliness and the rentilation of the works by mechanical means at the top into the shafts will prevent the diffusion of the stinking effluvia into neighbouring dwellings. (The bye-laws for regulating these trades, in force under the London County Council, should be referred to.)

Gut scraping, gut spinning, and sausage skin making.-This trade consists in the preparing of the intestine of the pig and sheep, by scraping, cleansing and twisting or spiming it, to form what is known as catgut.

The first operation consists in soaking the guts in water, or passing througl them a stream of water from a tap, sometimes after this the "guts" are sonked for some lays in brine. The process of scraping is performed either with a wooden scraper, or the back of a kinife, so that all the soft parts are detached. The guts are then further suaked, and if they are intended for use for sausage skins they are simply packed in salt in barrels and sent away. If, however, they are to be made into catgut, they are sewn together and twisted on a spinning wheel into cords of the required thickness. If intended for use as violin strings, they can only be made from the finest and freshest guts. It is quite obrious that the sources of nuisance arise: (1) from stale and offensive guts; (2) from dirty and unsuitable workshops, and (3) from improper storage of waste material. (The bye-laws in operation in London to govern these trades should be referred to.)

Unless one has harl experience of the disgusting nature of the stench arising from some of these places, it is quite impossible to realize it. Dr. Ballard says, "Speaking generally, gut scraping and gut spinning establishments are the most intolerable of nuisinces, wherever they may chance to be 
located. Within the workshops the stench is inconceivably horrible; few persons unaccustomed to it could bear to remain for a single minute in some scraping rooms."

In some of the large towns these businesses have become so objectionable that the smaller men have removed to rural districts outside the town, where in a shed in a field they have commenced operations. I myself have had personal experience of these in rural districts and have seen the horrible nuisance they will create hundreds of yards away. In one case I remember a nuisance was cansed through the waste water going into the sewer, producing a nuisance through the sewer ventilators, nor was this all, the sewer a small one, owing to an insufficient supply of water for the work, was partially occlucled by the decomposing solid animal filth which was allowed to pass into it. Without special order from the Local Government Board, a rural authority has uo power to make bye-laws to enforce a proper carrying on of this very offensive trade.

Bone boiling. - This is a trade which is at times productive of serious nuisance: (1) because stale and putricl bones are conveyed and stored, and ( $(\boldsymbol{z})$ during the boiling the steam is very offensive, while the bones after boiling, if heaped together as they generally are, give rise to a nasty ammoniacal odour, which is offensive and persistent. The way to obviate these sources of nuisance is first of all the conveyance of the bones in closed receptacles, tarred bars are highly spoken of, and the boiling of them by steam jacketed pans. "If boiled by fire the steam must be conveyed by suitable pipes from the boilers into a shaft and either burnt or diffused in the air at a good altitude. The bones after boiling while they are stored shonld be covered over by tarpaulins so that exposure to the weather is lessened. Or they may be dried in a suitable chamber after withdrawal from the boilers, by means of coke fires, the steam being allowed to escape or being condensed.

The manufacture of artificial manure.-This perhaps is one of the largest inclustries which give rise to nuisance, and the processes and materials employed are very numerous. The chief varieties are the phosphatic nitrogenous and saline. The phosphatic are derived from coprolites, phosphorite, and other minerals, bones, guanos, char dust from sugar retineries, supar scum, \&c. The nitrogenous materials are blood, animal flesh, guano, shoddy, scutch, and sometimes night soil. The saline are common salt, sulphate of ammonia, nitrate of sodium, $\mathbb{E}$. Most of these manures are made by the agency of sulphuric acid. The acid used is generally the crude chamber acid made from pyrites, and containing therefore arsenic in variable quantity, the amount sometimes being large, and this must 
be borne in mind in considering the nature of the vapours given off.

In the making of superphosplate, the coprolites are first powdered, or bones if they are used, crushed and then mixed either separately or together with sulphuric acid. This process is always done under a sherl, and this is as a rule lighted and ventilited from the top. Mixing is done in two ways, by hand or mechanically. The mixer generally consists of a covered vessel raised from the ground or on an upper floor, sometimes it is quite closed but sometimes only partially so; the acid is generally run in from a tank on a ligher lerel, the mixing usually takes about four or five minutes. A pasty mass is formed which runs out of the mixer into the "hot den." This is generally a brick chamber with a pared floor. In this den the manure remains to set and the time varies from twelve hours to three or four days. It is then dug out and removed to another part of the building. As a result of chemical action great heat is produced, exceeding $200^{\circ} \mathrm{F}$. The vapours given off contain a large quantity of moisture and also fumes of a compound of fluorine, silicon tetra fluoride, and these are decomposed by the moisture into hydroftuosilicic acid. Other common manure making processes are as follows :-

Dissolved Guano is mide by acting on Peruvian guano with sulphuric acid; the process is practically the same as for superphospliate, but in adlition to the gases given off in that manufacture, organic vapours of an unpleasant kind are erolved.

Leather, shoddy, fish, blood, and scutch are also acted on by sulpluric acil for the purpose of manure maling. While in some places human excreta are converted into a poudrette, first of all by condensation after the addition of a little sulphuric acid to fix the ammonia, and then sometimus by the addition of superplosphate.

The offensiveness of manure works varies immensely with the structure of the works and the precautions taken to abate nuisance, and also with the materials dealt with. The nuisance may be reduced to a minimum-e.y., Proctor \& Rylands, in Birmingham, right in the most populous part of the town (and very large works), is hardly ever complained of ; but in some instances works have proved vile nuisances at a distance of over four miles, and although it is difficult to prove actual or permanent damage to health, there is no doubt whatever that they are potent factors in reducing the vitality of those frequently exposed to their effluvia.

The sources of nuisance at manure works are: (1) the reception of riw material; (2) the preparation of this; (3) the process 
of manufacture or mixing; (4) the removal of the hot manure; 5. accumulations of the manufactured article.

(1). As a rule the crreat luulk of raw material is not a scrious nuisance, though boiled bones of ten are, while shodhy, if damaged by trinsit, is apt to give off umpleasant odours.

(2). In the preparation of material we may have nuisance from bone boiling or flesh boiling.

(3). The chief source of nuisance, however, is nearly always from the mixing, where rapours hoth irritating and offensive are disengagerl. If the manure is male in open ressels the nuisance is at its greatest, but it can be lessened, as I shill show, by the use of proper apparatus and other precautions.

(4). The removal of manure after mixing is also il serious source of nuisance, owing to the heat produced, and this can be obviated by the hot den, because this prevents the escape of the vapour's into the air, if properly constructed.

(5). In addition to these processes, the stornge of made manure causes at times great nuisance, especially in those cases where it is allowed to dry by spontaneous heating, particularly in the case of scutch manure works.

The following are the methods found most effectual in dealing with these nuisances:

1. Storage and reception of material.-This must, from the very nature of the works, be frequently offensive, and a creat deal can be done to improve affairs by transporting all offensive nuatter in closed tanks, chrums, or carts. The heaps of material may be covered up when stored, with earth or charcoal or other material; while night-soil should be kept in close tanks, and pumped up when required for use.

2. The Preparation.-This should only be done in closed chambers where the air is drawn off by means of a fan or slatft. When scutch is used it can be leated by steam in pressure pans, the fat extracted after it has cooled. Another plan is to heat it with steam and sulphuric acid and then express the fat by hydraulic pressure in a closed vessel while steam is in jected into it.

3. The nuisances arising from mixing are dealt with in many ways. Some of the rapours are condensible by cold, some soluble in water, while others can be destroyed by fire. All processes are in actual use.

In superphosphate maling the use of a long flue is sufficient to cause condensation and prevent nuisance, and this is adopted in Vickers's works in Manchester and at Morris and Griffin's in Wolverhampton, and in other places. These flues must be of great length to be efficacious, $200-250$ fect, and even then fluorine and arsenic fumes are still recognizable.

Scrubbers or cascades are in use, notably at Newton's, in 
Bermondsey, as a means of condensation. These are specially useful when there is no room for a long condenser. In this arrangement the vapours meet with a series of small streams of water, or cascades, falling from a tank and broken by a series of shelves; these in falling cause a racuum and draw the condensible vapours from the hot den and absorb them.

The fire is important in those works where there are prorluced nitrogenous vapours, which are not condensible, and the fire or furnace is often super-added to condensing apparatus in such works, especially where fish, excrement, blood, or garbage are worked up.

At Proctor \& Rylands', Birmingham, a flue takes up the fumes from the hot den and mixer, and then a fan forces these into an underground tank of water, constantly changed. Any gases escaping condensation are finally passed through the fire.

Dr. Ballarid in his report before referred to, speaks approvingly of the long flue if properly constructed, and if the vapour's are not hurried along it too fast. He also states that it is conclusively proved that good results are attainable from scrubbers or condensers, provided that they are not too small and the water is used in sufficient quantity:

4. The nuisance arising from the remoral of the manure from the den or mixer is now the chief cause of trouble in manure works, as no good remedy has yet been proposed for this, Dr. Ballard suggests either that the manure should be allowed to remain longer before removal and so allowed to cool, and secondly that means should be taken to expedite the cooling.

j. The general nuisance arising from the works, other than in mixing, can be lessened by uning closed buildings only, and drawing off the air by fans into condensers and furnaces: kiln drying should not be allowed on open kilns.

\section{Nuisances caused by dealing With Vegetable MatTers.}

Distillation of Wood.-Wood is heated or distilled for the production of charcoal and also for the manufacture of acetic acid, generally termed pyroligneous acid and "naptha" or methylic alcohol. Wood tar and creosote are also produced. The process adopted is generally as follows:- Wood in pieces is packed in iron boses or trolleys and run into an oven, heated by fire, having an exit pipe through which the rolatile matters and gases pass. Some of these are considerable and some are not. In the first place we have tar, water, and pyroxilic spirit, and in the latter chiefly gases of hydrocarbon nature. The plan generally adopted for condensation is the providing of nearly horizontal pipes which run backwards and forwards in a trough 
or troughs containing water. Sometimes, however, the water is omitted. The tar and liquids then run into an underground tank from which they are removed as occasion requires. The gases are usually burnt either under a fire or at the end of the escape pipe, or diffused in the air by means of a tall chimney.

The sources of nuisances are: (1) escape of fumes from the ovens, and although the quantity escaping is very small it is marvellous how irritating and penetrating it is; $(2)$ the escape of fumes during the drawing of the ovens; (3) the escape of some of the fumes from the condenser, however well it is constructed; (4) the nuisance caused by the after treatment of some of the products, especially the tar, which is further distilled for the purpose of making naphtha and pitch.

These nuisances, although easily abated in theory, are very difficult to abate in practice, and I have known of one case where a most intolerable nuisance was created at a country house half a mile away from works conducted on fairly good principles.

The modes of abating the nuisances are as follows:

(1). Careful construction of ovens and careful luting of doors during heating.

(2). Careful drawing of charges and luting at once the lid of each box.

(3). The burning of incondensible gases preferably beneath a furnace.

(4). The provision of a proper closed and ventilated place for the distillation of tar and the drawing of the charge.

Oxalic acid making is sometimes complained of as giving rise to nuisance. Sawdust is heated with caustic alkali in a pan and kept stirred, when the whole has been boiled down to a paste it is removed from the pans to a drying floor. The mass is lixiviated or washed with water and crystallized. It is then boiled with lime by which oxalate of lime is formed, and this is decomposed with sulphuric acid and the solution of oxalic acid is crystallized. To oxidize colouring matter a little nitric acid is sometimes added.

Unpleasant vapours are given off in the first part of the process, which are sometimes described as "sickly." Pungent and irritating fumes when the oxalate is hoiled with sulphuric acid, and lastly when nitric acid is used to bleach, nitrous fumes are evolved. 'These nuisances can be prevented by covering the pans in such a way that the fumes will be aspirated into a condenser or scrubber, or diffused from a tall chimney.

Paper works are productive of nuisance in two ways: (1) by boiling esprarto grass with alkali with the subsequent recovery of the alkali; and (2) by the pollution of streams with lime or

TOL. XVI. PART IV. 
organic refuse. When esparto grass is boiled with soda, both the first boiling and the subsequent wash water have an odour said to closely resemble senua tea.

The worst part of the nuisance, however, is that connected with the recovery of the soda, when this is heated in the open air and the resinous and other fumes are allowed to escape. Both these nuisances are easily remedied, the first by the provision of suitable boiling pans and a covered tank for the reception of the boiled charge, and seconlly the provision of suitable evaporators for the recovery of the soda of which there are several now in use, viz., Rockner's and the Porion-Davis. As regards the nuisance caused by polluting streams this depends very much on the relative size of the stream and the quantity of waste water. Near Birmingham, nuisance has been caused by waste water from a paper works where soda and esparto grass are not used. Lime is used with rags and some other materials, and the efluent after precipitation and filtration is run into the stream. No nuisance is caused at first, but further down secondary decomposition takes place, and eftuvia rising from the stream are complained of.

Manufacture of India-rubber.-Nuisances arising from this trade liave been reported at 300 or 400 yards from the works. They are due to the following four causes: (1) the boiling of the rubber, during which steam arises having sometimes a very offensive odour; (2) escape of fumes of naphtha in the processes of manipulating the rubber; (3) the steam discharged from the vulcanisers, after vulcanisation is complete; (4) the drying of the sheets of vulcanised rubber on steam chests after washing them, the odours given off being like those of burning Indiarubber.

The first cause can be obriated by boiling the rubber in closed pans, the steam being either condensed or burnt in a furnace. The others by covering the spreading plate when naphtha is used by a box, the air of which is exhausted by a. fan, and the naphtha either condensed by cold in a freezing machine or absorbed by oil. The general air of chamber's containing naphtha can be drawn off by a shaft and fan, and discharged into a tall climney.

Oil boiling, varnish making, \& c.-Oils and fats are compounds of acids with glycerine, and when they are heated to a decomposition temperature a substance called acrolein is produced, which is extremely irritating to the eyes and nose. In rarious processes, such as oil boiling, varnish making, and floor-cloth making, this heating of oil and production of acrolein takes place, unless special precautions are taken to prevent nuisance. In many instances it is desirable to heat the oil in open pans, 
and even when this is done nuisance may be obviated by adopting the process of Messrs. Heywood \& Lloyd. The pan is fitted with a fumnel-shaped cover, in the corner of which is an outlet pipe; this is connected with a shaft in which a fan is worked, and all vapours are drawn off through it and are sent into a continuous pipe condenser, and then either through water or into the furnace of a fire; so that although the centre of the pan is open, no fumes escape through it owing to the strong inward draught caused by the fan in the outlet pipe. In some processes the fumes arising are subjected to a cascade in a scrubber, and are condensed in this way.

\section{Nuisances caused by dealing with Mineral Matters.}

The Manufucture of Coal Gas.-Conl is heated in closed retorts, and gas, water, tar, and ammonia pass off. The tar and water are condensed speedily with some of the ammonia, the gas or rather mixture of gases pass on first of all to the scrubbers where ammoniil is absorbed, and then on to the purifiers, where the carbonic acid gas and sulphuretted hydrogen are absorbed by lime and oxide of iron. If carbon disulphide is also removed a special small purifier containing sulphide of calcium is interposed. It is of course a well-known fact that odours of an unpleasant type escape from all gas works, but if the processes are not carried on carefully the nuisance becomes unbearable.

The sources of nuisance are : (1) escape of smoke, \&c., from the retort house ; $(2)$ the emptying of the purifiers; (3) the revivication of the oxide of iron; ( 4 ) the exposure of tar, $\&$ c., to the atmosphere; and (5) the removal of the various refuse substances from the works.

The first source of nuisance depends on careful charging of the retorts and the proper withdrawal of the charge after complete coking and the quenching of the coke. The chief nuisance is that arising from the emptying of the purifiers; this can be reduced by watering the lime first and carefully covering up with sacking all parts not actually being dug out at the time, and the reception of it into cuvered trucks and barges for removal. I liave known serious nuisance to be caused at a gentleman's residence by the passing along the canal of gasworks material, even when the house was a long way off but situated on a higher level.

The inanufacture of Sulphate of Ammonia.-In this process the "gas liquor" is mixed with lime and distilled ammonia is given off and received into sulphuric acicl. Sulphate of ammonia is formed and crystallized out. As the gas liquor contains sulphide of ammonia, sulphuretted hydrogen is evolved, and this 
is the main cause of nuisance from such works. It may be abaterl in two ways: (1) by burning the sulphuretted hydrogen, when it will be decomposed into water and sulphur dioxide; this, however, is itself a pungent and irritating gas and must be sent into a high chimney or else it will cause serious nuisance; (2) It (sulphuretted hydrogen) may be absorbed by chemical agents such as lime or oxide of iron mixed with sawdust, although in the latter case precautions have to be taken to counteract the effects of the heating which takes place.

Distillation of Tar.-In this trade coal tar mixed with more or less ammoniacal liquor is distilled. There are four products: (1) light oils; (2) heavy oils or creosote oils sinking in water and containing carbolic and cresylic acids; (3) anthracene oil, still heavier; and (4) pitch. The causes of nuisance are as follows :

1. The transference of the tar in uncovered barges and tanks, the chief odour arising from sulphide of ammonium.

2. The escape of offensive distillation products, mostly coming off at the end of the distillation.

3. The escape of a dense white vapour from the pitch being run off while liot.

4. The escape of offensive vapours from the pitch oven.

5. The use of creosote oil as a fuel, where there are no proper arrangements for its consumption.

All these nuisances can be successfully dealt with by transference of the crude material in air-tight tanks, absorption of sulphicle of ammonium by hydiated oxide of iron, passing the gases through water and burning up those that escape in a furnace fire, and the use of creosote oil only in properly constructed furmaces, and ruming the pitch into a closed tank to cool.

The manufacture of Carbolic acid.-The carbolic oil from tar distillation is treated with caustic soda which separates out the carbolic and cresylic acids from the tar oils. It is siphoned off these and the alkaline liquid is super-saturated with sulphuric acid. The acids separate, are ladled off and distilled by fractional distillation curried to dryness, a light coke being left in the retort. Nuisances are caused by the odour of carbolic acid, by the escape of offensive gases at the end of the distillation, and by removing the coke from the retorts. The odour of carbolic acid is reduced by receiving the condensed liquids into covered vessels, while the gases are condensed by a worm as far as possible, those not condensing being drawn by a steam injector into a solution of lime or water, by means of which sulphuretted hydrogen is arrested, while others are conveyed by a pipe into the ash-pit of a furnace.

Nuisance from the coke is prevented by completing the distillation and not removing the coke until it is cold. 
The manufacture of Alkali.-In this process sulphuric acid is made to act on sodium chloride when heated. Hydrochloric acid gas escapes, and is condensed by a scrubber in suitable towers. The salt cake left is treated with chalk and fine coal, when sodium carbonate and calcium sulphide are formed. This mixture is called black ash, and the soda is obtained from it by lixiviation with water. The residue is termed tank waste, and it is from this that nuisance, if any, will chiefly arise, because it consists of ill-clefined compounds of calcium and sulphur, some of which by oxidation become dissolved in water, either from rain washings or other causes.

This waste can be utilised and the sulphur recovered, either by Mond's process, in which air is blown through the waste, when the sulphur compounds are oxidised to sulphite and sulphate. These compounds are washed out and treated with hydrochloric acid and steam, when sulphur precipitates and is collected. At the St. Rollox works, Glasgow, Mactear's process is in use. The waste heaps are permeated by springs, and the liquid coming away from them holds in solution calcic sulphite and hyposulphite. Hydrochloric acid is added, and the salts are decomposed, sulphur being precipitated and sulphur dioxide evolved. Any sulphuretted hydrogen evolved from the sulphide is decomposed by the sulphur dioxide, more sulphur being thrown down; so that provided there is enough hyposulphite no nuisance from sulphuretted hydrogen can occur, and if not this can be added in requisite quantity.

The manufacture of oil of vitriol.-Sulphur or iron pyrites is heated, and the sulphur dioxide fumes are conveyed into a leaden chamber along with steam and the higher oxides of nitrogen produced by acting on nitre with sulphuric acid. The acid collects on the floor of the chamber, and is evaporated down in glass retorts.

Nuisances may arise from the sulphur dioxide or nitrogen oxides escaping from the chimney, furnaces, or lead chambers, and during concentration of the acid, by breaking of a retort, but all these nuisances are easily obviated by proper fittings.

Manufacture of bleaching powder.-Chlorine, made in several ways, is conducted to chambers where lime is laid on shelves in thin layers, when it is absorbed by the lime, and the so-called chloride of lime produced. The sources of nuisance are: the escape of chlorine by leakage from the chambers and from the powder while packing in casks. This can be obviated by exposing the lime in one chamber first, and then by a fan driving the unabsorbed chlorine into another chamber, where it will combine with the fresh lime; or the chamber may be divided into two parts, and when the lime in the first part is 
saturated, allowing the unabsorbed chlorine to act on that in the other compartment.

It has been proved that the transference to the casks need cause no nuisance, as the powdcr may be packed in the casks by means of a direct tube of sacking from the chamber where it is made.

Galvanizing Iron.-In this process iron is first cleaned by dipping in a bath of lydrochloric acid, and then dipped into a bath of molten zinc. If the iron were quite pure, lyodrogren only would be given off, but owing to impurities in it (carbon and sulphur chiefly), vapours are given off which are sometimes a nuisance, while there is generally some nuisance from arsenical fumes rising.

These fumes are directly injurious to health, and should not be allowed to escape at a low level, as is generally the case, into the atmosphere. They should be abstracted from the building by mechanical arrangements into tall chimneys and so diffused into the higher layer's of the atmosphere. The spent pickle always contains a large quantity of free acid and unless this is neutralized or removed in some way it will damage the masonry of the sewers or pollute the watercourse into which it is discharged.

Brick burning is a very common operation and frequently causes nuisance to those in the neighbourhood. When bricks are burnt in well constructed kilns, the muisance is slight; when, however, "clamp burning" or the burning of bricks with breeze and household refuse in alternate layers is carried on grave complaints from smoke, sulphuretted lyydrogen, and organic vapours of a disgusting kind are made, therefore this kinil of burning should be prohibited in the neighbourhood of towns or collections of dwellings.

The last nuisance I shall bring before you is that of Portland Cement making.-Clialk and clay are ground together with water and made into a mud. It is then called "Slurry." This is dried and burnt in kilns, and it is the emanations from this burning which give rise to the trouble. 'Jhese consist of carbonic acid and sulphuretted hydrogen, and sometimes hydrocyanic acid or some volatile cyanide, so much so that in a case at Southampton, the gravel in the neighbourhood was coloured blue from the production of cyanide of iron. In addition to this, solid deposits of soot and dust are also formed.

It appears that the most effective plan of doing away with nuisance is to discharge all fumes into a very ligh stack 150 to 200 feet in height.

And now, gentlemen, my task is done, no one is more aware than myself of its deficiency. I have endeavoured in the short 
time at my disposal to bring under your notice those nuisances which are most likely to be met with by the sanitary officer in the course of his daily work, and although he may have difficulty in proving in any particular case that a nuisance is causing visible injury to health, it behoves him to remember that the science of hygiene is simply the doctrine of cleanliness, and that it is therefore the first duty of all engaged in sanitary work to remove as far as possible all impurity and dirt, whether in food, air, soil, or water, as only by the most perfect attainable cleanliness can we hope to reach the ideal of the sanitarian, the mens sanci in corpore sano.

Offensive Trades specified in Sec. 11\% Public Health Act, 1875.

1. Blood boiler.

2. Bone boiler.

3. Fellmonger.
4. Soap boiler.

5. Tallow melter.

6. Tripe boiler.

7. Any other noxious or offensive trade (ejusdem generis).

Bye-Laws made by the Local trowerment Board with respect to the tracles of :-

1. Blood boiler.

2. Blood drier.

3. Bone boiler.

4. Fellmonger.

5. Tammer.

6. Leather dresser.

7. Soap boiler.
8. Tallow melter.

!. Fat melter or extractor.

10. Tripe boiler.

11. Glue maker.

12. Size maker.

13. Gut scraper.

\section{To these should be added-}

1. Fish and bacon curers.

2. Flesh boilers (for cats' meat, sc.
3. Animal charcoal makers.

4. Artificial manure makers.

Methods of preventing muisance from Offensive Trades.

1. Solid offensive refuse must be separated from liquid, the solid portions being removed in closed impervious vessels.

2. Liquid refuse must be conducted away by proper drains, denderants being used.

3. Iapours and efthuia should he treated by a combination of the following methods (the particular combination depending upon the trade) :-

1. Condensation by cold.

2. Absorption by water, or chemicals.

3. Destructive distillation by heat in a closed vessel.

4. Combustion of all gases that can be burnt.

5. Discharge of gases into the air at a great height. 